Brazilian Journal of Microbiology (2009) 40: 663-669

ISSN 1517-8382

\title{
RAPID POLYVALENT SCREENING FOR LARGE-SCALE ENVIRONMENTAL SPIROPLASMA SURVEYS
}

\author{
Frank E. French ${ }^{1}$; Robert F. Whitcomb ${ }^{2}$; David L. Williamson ${ }^{3}$ ' Laura B. Regassa ${ }^{1^{*}}$
}

\author{
${ }^{1}$ Department of Biology and Institute of Arthropodology and Parasitology, Georgia Southern University Statesboro, GA 30460 \\ USA; ${ }^{2}$ Vegetable Laboratory, U. S. Department of Agriculture, Beltsville, MD 20705 USA; ${ }^{3}$ Department of Anatomical \\ Sciences, State University of New York, Stony Brook, NY 11794 USA
}

Submitted: June 28, 2008; Returned to authors for corrections: September 04, 2008; Approved: May 03, 2009.

\begin{abstract}
Surface serology is an important determinant in Spiroplasma systematics. Reciprocal antigen/antibody reactions between spiroplasmas and individual antisera delineate the 38 described groups and species. However, reciprocal serology is impractical for large-scale studies. This report describes a successful, streamlined polyvalent screening approach used to examine isolates from an environmental survey.
\end{abstract}

Key words: spiroplasma; mollicutes; serology; deformation test.

The spiroplasma deformation (DF) test is a central feature of spiroplasma systematics that examines the cell surface antigenicity of clonal isolates. Originally adopted for detecting Spiroplasma poulsonii (then a "noncultivable" agent causing sex ratio abnormalities in Drosophila willistoni), the technique was modified for general use in spiroplasma systematics $(15,16)$. The DF test has subsequently been used, in part, to define spiroplasma groups $(6,12,17)$ and species (1). There are currently 38 described serogroups (reviewed in $7 ; 14$ ), and some of the groups are further subdivided. For example, group I has eight subgroups that include five characterized species (7). The serogroup I subgroups have 0.986-0.991 16S rDNA sequence similarity, yet distinctive serologies (5).
Horse flies or tabanids (Diptera:Tabanidae) are a rich source of spiroplasmas $(2,4,13)$. A large-scale biodiversity survey of tabanid-associated spiroplasmas began in the southeastern United States in 1987, with most spiroplasmas being isolated from female tabanids in southeast Georgia (Bulloch County). Based on DF tests, nine groups and five subgroups (of group VIII) were isolated in this initial survey. When the study was extended to tabanid-associated spiroplasmas in Costa Rica, Ecuador and Australia, the number of putative groups increased even more rapidly than in the southeastern United States. To date, over 1,000 spiroplasma isolations have been completed from tabanid flies as part of this environmental survey. 
Faced with a deluge of new isolates, the standard DF test that individually examines the reciprocal serology of each antigen/antiserum pair was impractical. Instead, a polyvalent screen (PVS) was adopted that used mixtures of antisera directed against spiroplasma strains known to occur in tabanids. The initial PVS trial screened more than 400 isolates from the southeastern United States and the Costa Rican highlands using a total of 13 antisera (all against known U.S.A. tabanid-associated strains) distributed in 6 screening cocktails (Table 1). As the study progressed, the number and content of the screening mixtures were modified. For example, the screening array was expanded to 24 antisera in 12 cocktails to process isolates from the Costa Rican lowlands (Table 1), and later it was expanded further to include 38 antisera in 12 cocktails to screen Australian and Ecuadorian isolates (Table 1). Initially, the components of each cocktail were selected based on serological relationships. For example, one antisera cocktail (Table 1, cocktail 2) contained all group VIII strains that had low level cross-reactivity (8). As the study progressed and novel serogroups were identified, the new antisera were included in the cocktails with the fewest number of component antisera. This approach was dynamic and efficient, as antisera against new serogroups/strains could be added to screening cocktails as needed.

The screening cocktails were generated by combining equal volumes of each antiserum in M1D medium (10) to achieve a final dilution of 1:10 for each. All antisera were combined with other sera successfully, in that all cocktails reacted strongly when challenged with an antigen homologous to a component of the cocktail. These cocktails were routinely stored at $4^{\circ} \mathrm{C}$ for up to one year with no detectable loss in reactivity. Isolates were screened by mixing an equal volume of actively growing spiroplasma culture with each antisera cocktail in microtiter plate wells (20 $\mu \mathrm{l}$ each), and plates were incubated at room temperature for 30 minutes. Samples from each of the PVS reactions were examined by dark-field microscopy at $1200 \mathrm{X}$ for cell deformation (Figure 1). Reaction mixtures that exhibited $\geq 50 \%$ cell deformation (e.g. clumping, blebs) were considered positive for antigenic reactivity to a component of the cocktail.
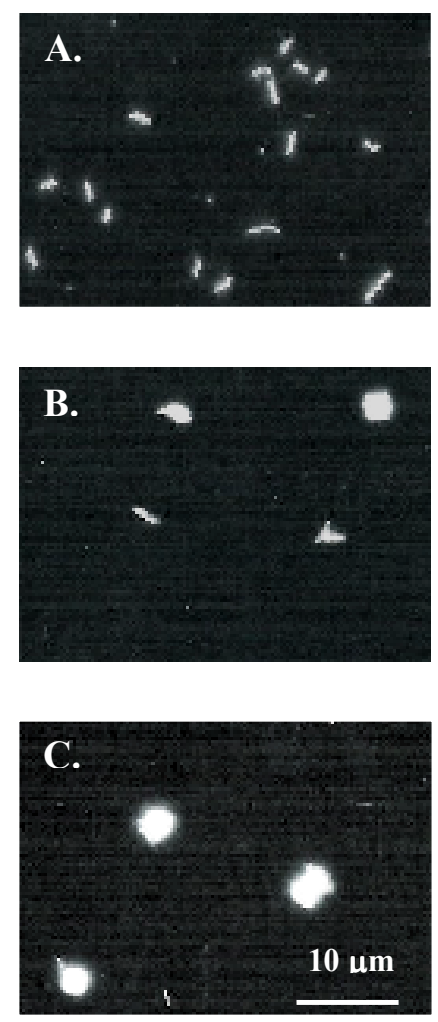

Figure 1. Deformation (DF) test with Spiroplasma citri strain Maroc R8A2 and homologous antiserum with an endpoint DF titer of 1:2048. Cultures were incubated for 2 hours at room temperature without antiserum (A) as a control for normal morphology or with varying dilutions of antiserum exhibiting intermediate (B) to strong (C) deformation reactions. For image generation, cells were fixed overnight in $1.5 \%$ glutaraldehyde, resuspended in fresh M1D medium, and then photographed under dark-field illumination. 


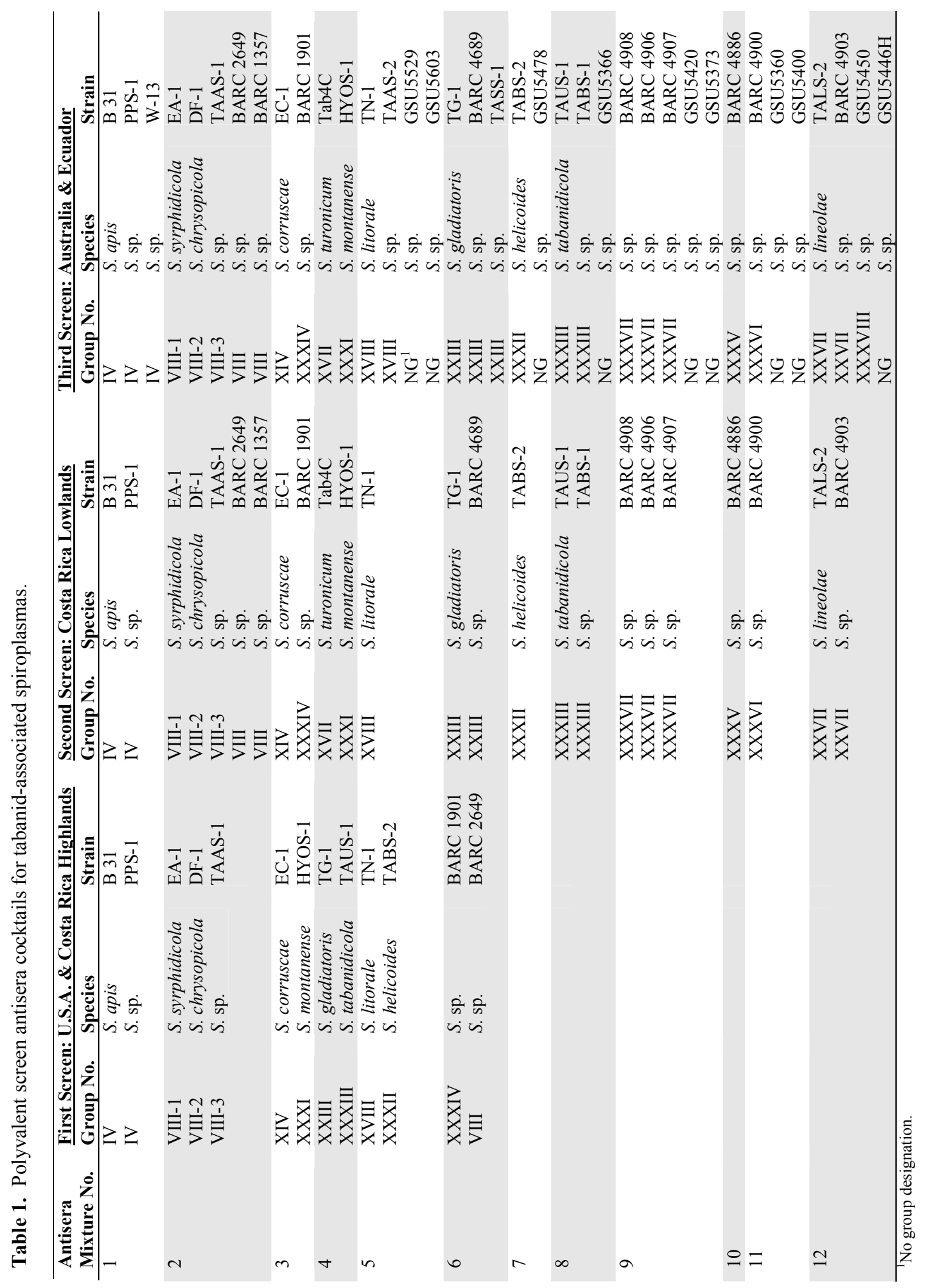


French, F.E. et al.

The PVS rapidly revealed that most of the new isolates were matches to known serogroups. All isolates that were positive to a screening cocktail were tested in individual DF tests using each of the component antisera; the two-fold dilution series examined antisera titers of 1:20 to $1: 2560$. Generally, an isolate reacting with antiserum to a described group at a concentration $\leq 1: 320$ was considered to be a member of that group. An isolate exhibiting no or only low levels of cross reactivity $(1: 20-1: 40)$ to all antisera in the PVS was tentatively given candidate status as a new serovar. When the original isolations were mixed cultures or when adaptation to laboratory media was required for optimal morphology (14), additional passages and/or limiting dilution cloning $(3,11)$ were necessary before serological placement could be achieved.

As new groups emerged, antisera to triply-cloned strains were prepared and added to the PVS and DF tests. For the described study, 23 clusters of isolates with novel serology (i.e. putative new serogroups) were identified. Antisera production was completed as described previously $(8,9)$, with the substitution of MPL $₫+T D M, M P L \AA+T D M+C W S$ or TiterMax ${ }^{\circledR}$ Gold (Sigma-Aldrich Chemical Company, St Louis, Missouri, U.S.A.) as the adjuvant. No booster injection was required when TiterMax ${ }^{\circledR}$ Gold was used. Sera were aliquoted and stored at $-70^{\circ} \mathrm{C}$ or lyophilized. Animals were cared for in accordance with approved guidelines set forth in the Guide for the Care and Use of Laboratory Animals (NIH Publication No. 86-23), and their use was reviewed and approved by the Institutional Animal Care and Use Committee at Georgia Southern University.

With hundreds of spiroplasma isolates from tabanid flies, it was prudent to develop an efficient preliminary screening system. The PVS procedure permitted initial screening of new isolates with 6-12 antisera mixtures rather than 13-38 individual antisera, streamlining the process and reducing the amount of antisera required. For example, the ten field isolates from Ecuador required $27 \mathrm{PVS}$ and $150 \mathrm{DF}$ tests to resolve five new groups and one geographic variant. The same serological analyses without the PVS test would have required an estimated 1,178 DF tests. Inclusion of the PVS test reduced the amount of antisera required by $44 \%$ and the time/labor commitment by approximately $85 \%$. As the number of new serogroups and species continues to increase, the need for streamlined serological screening becomes even more critical.

For large environmental surveys we suggest the following screening procedures: (A) complete a PVS for early isolate passages using antisera combinations of strains that are likely to be related (e.g. common host); (B) complete one to two rounds of dilution cloning for non-reactive isolates (i.e. those showing $<50 \%$ deformation) and then repeat the PVS; (C) triply clone non-reactive isolates, repeat PVS, complete DF tests versus all strains in cocktails that showed any level of cross-reactivity in the final PVS, and then produce antisera against any unresolved isolates (i.e. no reactivity at concentrations $\leq 1: 320$ ); and (D) use $16 \mathrm{~S}$ rRNAbased phylogenetic analyses to identify closely related strains and then DF test the isolate versus all closely related strains or groups not included in the PVS. As an example, screening data for environmental isolates from the Costa Rican highlands is shown in Table 2; this approach successfully identified 4 putative new species (represented by BARC 4886, BARC 4900, BARC 4908/4907/4906 and GSU5450); serogroup VIII isolates (BARC 4898/4899); and geographic variants (BARC 4901/4902/4903/4905) of S. lineolae (14). Further characterization is required for serogroup (12) or species (1) designations.

Inclusion of a PVS prior to DF tests makes large-scale environmental surveys to examine spiroplasma biodiversity and biogeography feasible, and the approach may have wider applications for other mollicutes that also rely on serology for classification. 


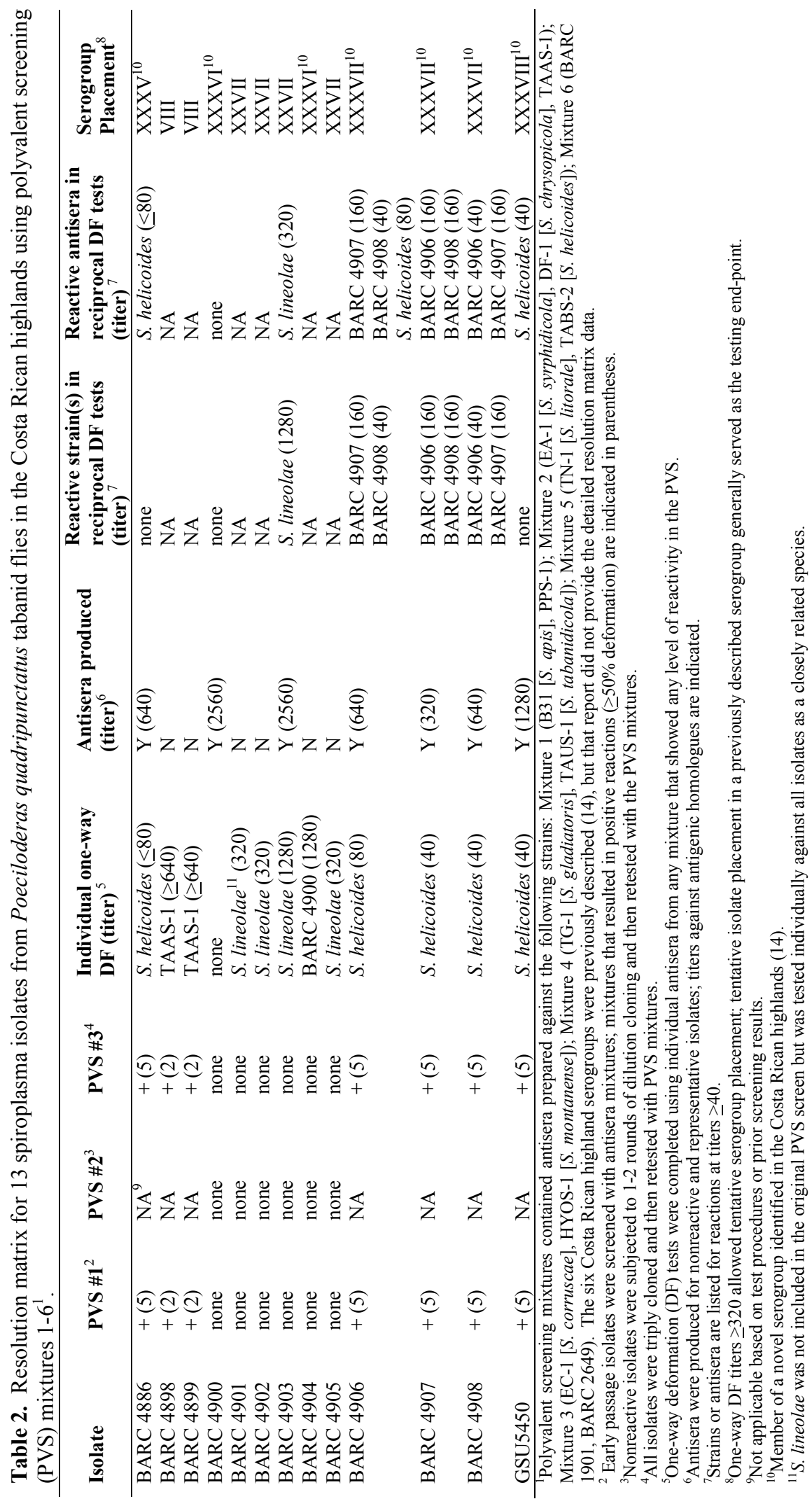


French, F.E. et al.

\section{ACKNOWLEDGEMENTS}

We gratefully acknowledge the laboratory support of James H. Oliver, Calloway Professor, and Craig Banks, Institute of Arthropodology and Parasitology, Georgia Southern University, Statesboro, Georgia U.S.A. We appreciate the support and guidance of Joseph G. Tully, Mycoplasma Section, Laboratory of Molecular Microbiology, National Institute of Allergy \& Infectious Diseases, Frederick Cancer Research Facility, Frederick, Maryland, U.S.A. This work was supported by the Georgia Southern University Faculty Research Committee; the National Geographic Society (6183-98, PI: French); a United States Department of Agriculture Cooperative Research Grant, Insect Pathology Laboratory, Beltsville, Maryland U.S.A., Agreement No. 583K47-0-007 (PI: French); the United States Department of Agriculture (98-35204-7019, PI: Regassa); and the National Science Foundation (DEB-0481430, PI: Regassa).

\section{RESUMO}

Triagem rápida para pesquisa ambiental de larga escala de Spiroplasma

A sorologia de superfície é um determinante importante na sistemática de Spiroplasma. Reações antígeno-anticorpo entre spiroplasmas e antisoro individuais delineiam os 38 grupos e espécies descritos. No entanto, reações sorológicas são impraticáveis em estudos em larga-escala. Esse relato descreve uma metodologia de triagem bem sucedida a ser empregada no exame de isolados em levantamentos ambientais.

Palavras-chave: siproplasma, sorologia, mollicutes, teste de deformação
1. Brown, D.R.; Whitcomb, R.F.; Bradbury, J. (2007). Revised minimal standards for description of new species of the class Mollicutes (Division Tenericutes). Int. J. Syst. Evol. Microbiol. 57, 2703-2719.

2. Clark, T.B.; Peterson, R.V.; Whitcomb, R.F.; Henegar, R.B.; Hackett K.J.; Tully, J.G. (1984). Spiroplasmas in the Tabanidae. Isr. J. Med. Sci. 20, 1002-1005.

3. Fazekas de St.Groth, S. (1982). The evaluation of limiting dilution assays. Immunol. Meth. 49, R11-23.

4. French, F.E.; Whitcomb, R.F.; Tully, J.G.; Hackett, K.J.,; Clark, E.A.; Henegar, R.B.; Rose, D.L. (1990). Tabanid spiroplasmas of the Southeast USA: New Groups, and correlation with host life history strategy. Zentralblatt fur Bakteriologie, Suppl. 20, 919-921.

5. Gasparich, G.E.; Whitcomb, R.F.; Dodge, D.; French, F.E.; Glass, J.; Williamson, D.L. (2004). The genus Spiroplasma and its nonhelical descendants, phylogenetic classification, correlation with phenotype and roots of the Mycoplasma mycoides clade. Int. J. Syst. Evol. Microbiol. 54, 893-918.

6. Junca, P.; Saillard, C.; Tully, J. G.; Garcia-Jurado, O.; Degorce-Dumas, J.R.; Mouches, C.; Vignault, J.C.; Vogel, R.; McCoy, R.; Whitcomb, R.; Williamson, D.; Latrille, J.; Bové, J.M. (1980). Caractérisation de spiroplasmes isolés d'insectes et de fleurs de France continentale, de Corse et du Maroc. Proposition pour une classification des spiroplasmes. C. R. Acad. Sci. Ser. D 290, 1209-1212.

7. Regassa, L.B.; G.E. Gasparich, (2006). Spiroplasmas: Evolutionary relationships and biodiversity. Frontiers in Biosci. 11, 2983-3002.

8. Regassa, L.B.; Stewart, K.M.; Murphy A.C.; French, F.E.; Lin, T.; Whitcomb, R.F. (2004). Differentiation of group VIII Spiroplasma strains with sequences of the $16 \mathrm{~S}-23 \mathrm{~S}$ rDNA intergenic spacer region. $J$. Can. Microbiol. 50, 1061-1067.

9. Tully, J.G.; Whitcomb, R.F.; Bové, J.M.; Saglio, P. (1973). Plant mycoplasmas: Serological relation between agents associated with citrus stubborn and corn stunt diseases. Sci. 182, 827-829.

10. Whitcomb, R.F. (1983). Culture media for spiroplasmas. In: Razin, S.; Tully, T.G. (eds.). Methods Mycoplasmology, vol. 1. Academic Press, New York, USA, pp. 147-158.

11. Whitcomb, R.F.; Hackett, K.J. (1987). Cloning by limiting dilution in liquid media: an improved alternative for cloning mollicute species. Israel J. Med Sciences. 23, 517.

12. Whitcomb, R.F.; Bové, J.M.; Chen, T.A.; Tully, J.G.; Williamson, D.L. (1987). Proposed criteria for an interim serogroup classification for members of the genus Spiroplasma (Class Mollicutes). Int. J. Syst. Bacteriol. 37, 82-84.

13. Whitcomb, R.F.; French, F.E.; Tully, J.G.; Carle, P.; Henegar, R.; Hackett, K.J.; Adams, J.; Williamson, D.L. (1997). Spiroplasma species,

\section{REFERENCES}


groups, and subgroups from North American Tabanidae. Curr. Microbiol. 35, 287-293.

14. Whitcomb, R.F.; Tully, J.G.; Gasparich, G.E.; Regassa, L.B.; Williamson, D.L.; French, F.E. (2007). Spiroplasma species in the Costa Rican highlands: Implications for biogeography and biodiversity. Biodiver. Conserv. 16, 3877-3894.

15. Williamson, D.L.; Poulson, D.F. (1979). Sex-ratio organisms (Spiroplasmas) of Drosophila. In: Whitcomb, R.F., Tully, J.G. (eds),
The Mycoplamsas, vol. 3. Academic Press, New York, USA, pp. 175208.

16. Williamson, D.L.; Whitcomb, R.F.; Tully, J.G. (1978). The spiroplasma deformation test, a new serological method. Curr. Microbiol. 1, 203207.

17. Williamson, D.L.; Whitcomb, R.F.; Tully, J.G.; Gasparich, G.E.; Rose, J.G.; Carle, P.; Bové, J.M.; Hackett, K.J.; Adams, J.R.; Henegar, R.B.; Konai, M.; Chastel, C.; French, F.E. (1998). Revised group classification of the genus Spiroplasma. Int. J. Syst. Bacteriol. 48, 1-12. 